\title{
A Snapshot of the Syrian Jihadi Online Ecology: Differential Disruption, Community Strength, and Preferred Other Platforms
}

\author{
Maura Conway, Moign Khawaja, Suraj Lakhani and Jeremy Reffin
}

\begin{abstract}
This article contributes to the growing literature on extremist and terrorist online ecologies and approaches to snapshotting these. It opens by measuring Twitter's differential disruption of so-called "Islamic State" versus other jihadi parties to the Syria conflict, showing that while Twitter became increasingly inhospitable to IS in 2017 and 2018, Hay'at Tahrir al-Sham and Ahrar al-Sham retained strong communities on the platform during the same period. An analysis of the same groups' Twitter out-linking activity has the twofold purpose of determining the reach of groups' content by quantifying the number of platforms it was available on and analyzing the nature and functionalities of the online spaces out-linked to.
\end{abstract}

\section{Introduction}

This article provides a snapshot of the 2017- 2018 Syrian jihadi online ecology that builds upon previous research conducted by the authors, ${ }^{1}$ a key finding of which was that jihadis on Twitter were subject to differing levels of disruption (i.e. account and content takedown). In particular, our "Disrupting Daesh" article underlined that pro- (so-called) "Islamic State" (IS) accounts were subject to far greater levels of disruption, as compared to a bucket of what we termed "Other Jihadi" accounts, including those affiliated with and/or supportive of Hay' at Tahrir al-Sham (HTS), Ahrar al-sham (AAS), the Taliban, and al-Shabaab. ${ }^{2}$ Also addressed in that article was the out-linking patterns of users associated with the aforementioned groups, where prominent social media and content hosting platforms, including Facebook, YouTube, Google Drive, and a range of generally lesser known platforms, including archive.org, JustPasteIt and Telegram, were visible. ${ }^{3}$ We thus emphasized the need to evolve existing research practices in this domain. Specifically, we noted the way in which researchers, counterterrorism professionals, policymakers, journalists, representatives of social media companies, and others focused on examining the intersections of terrorism and the Internet narrowed their focus, almost exclusively, to IS after they declared their so-called "caliphate" at the end of June 2014. In fact, many scholars in the field narrowed their focus even further to IS's Twitter activity. We recommended against continued analytical contraction of this sort and pointed to the need to maintain a wide-angle view of online activity by a diverse range of jihadis, and other violent extremists and terrorists, across a variety of social media and other online platforms. ${ }^{4}$

Having said this, the value of Twitter to jihadist groups, including IS, should not be underestimated. IS's supporters, including on Dark Web forums and elsewhere, have been implored to return to the platform, with a representative post stating "[w]e call upon you [supporters] day and night to return to Twitter". ${ }^{5}$ A wide range of "tricks and tips" have been circulated online by pro-IS users to seek to make this happen, including advice to pro-IS Twitter users on altering the terminology they use on the platform to avoid detection. Instructions are also routinely provided on IS and their supporters' Telegram channels on possibilities for 
avoiding contravention of Twitter's Terms of Service (ToS). ${ }^{6}$ A portion of the current article therefore remains dedicated to Syrian jihadi groups' Twitter activity, providing an accounting of Twitter's disruption of not just pro-IS accounts, but accounts supportive of other jihadi parties to the Syria conflict, including whether differential disruption continued to be observed. It demonstrates that the differential disruption issue is an important one; due to the shifting fortunes of, in particular, IS and HTS on the ground in Iraq and Syria (and more widely). In the face of IS's loss of their core physical territory, the continued-and potentially increasingimportance of online "territory" should not be underestimated. The suggestion in this article is not therefore that a focus on IS and their online activity should be dispensed with, but that if HTS - along with other Syrian jihadi factions-are significantly less-impeded online, then this differential disruption will most likely be an important asset for them and worth monitoring. This quite narrow comparison of the differential disruption of IS versus HTS versus AAS can also feed into larger discussions around internet companies content moderation practices, especially around what Facebook terms "dangerous organizations", 7 and the reasoning behind and impacts of these. ${ }^{8}$

One of these impacts has been the forced migration of especially IS to other online platforms and spaces, which adaptive behavior affects the overall complexion and structuring of the Syrian jihadi online ecology. There is a particular focus herein on Syrian jihadi groups' Twitter outlinking patterns. This includes quantifying the numbers of platforms being out-linked to, and describing and analyzing the types and purposes of these in order to provide a snapshot of the wider Syrian jihadi online ecology. Out-link analyses are a useful tool for broadening contemporary research on violent extremism, terrorism, and the Internet beyond social media to the variety of other online spaces in use by violent extremists and terrorists, and their online supporters. These include some groups' heavy reliance on content upload sites, along with patterns of out-linking to more mainstream (i.e. nonextremist) websites, including mainstream news media sites. By considering these other online spaces and their structures and functions, this article contributes to the growing literature on extremist and terrorist online ecologies and approaches to snapshotting these.

The article is composed of five sections. The first section addresses terminology, specifically our use of the terms "ecology" and "snapshotting". Section two describes our methodology, including case selection and the social media monitoring techniques employed by us. Our findings are described in sections three and four, which address differential disruption and its impacts on groups' online community strength and the nature and workings of the wider jihadi online ecology respectively. Our conclusion has an emphasis on directions for future research.

\section{Terminology}

Media ecology has a long history in media and communication studies, dating to at least the early 1970s, ${ }^{9}$ but was first deployed in the study of online radicalization and terrorism by Awan, Hoskins and O'Loughlin in their 2011 book Radicalization and the Media: Connectivity and Terrorism in the New Media Ecology. ${ }^{10}$ There they drew attention to the way in which:

The new media ecology is dependent first and foremost on the classification, circulation and organisation of 'information', which together forge an 'information infrastructure'...[T]his infrastructure involves an increasing convergence of "standards, categories, technologies, and phenomenology." 11 In terms of radicalisation, the information infrastructure affords not just a 
framework through which actors, institutions, and the practices of these groups and the relationships between them can be mapped out, but rather a more dynamic configuration of the nodes and networks ushered in through the connective turn" [our italics] (124).

Subsequent analyses by online extremism and terrorism researchers appear-because none actually discuss the conceptual underpinnings of the terms they use-to adopt a more basic biological approach, in the sense of a focus on ecology revolving around the relationship between the environment and living organisms and on ecosystems revolving around the study of specific places and environments. In this approach, ecosystems are components of broader ecologies. So, for example, Clifford and Powell focus on the "Islamic State ecosystem on Telegram" whereas Macdonald et al. level-up with their focus on "Daesh, Twitter and the Social Media Ecosystem".12 In this article and in previous work, we utilize the concept of the "jihadi online ecology" to point to our interest in the quantity, distribution, and nature of online platforms and spaces (i.e. ecosystems) inhabited by jihadis and the interplay of these, as impacted by sociotechnical forces (i.e. their environment). ${ }^{13}$

Like Awan, Hoskins and O'Loughlin we are skeptical of the ability of the terms "map" or "mapping" to capture the "dynamic configuration" of contemporary online ecologies; we prefer to use the term "snapshot" or "snapshotting" to refer to our findings. This is to underline (i) their ephemerality, given the fast-changing nature of both cyberspace and the groups active within it, (ii) the effectiveness of multiple iterations of the same or similar research to successfully capture the latter, and (iii) the utility of investigating complex online ecologies from a collage of different theoretical, methodological, or other perspectives.

\section{Methodology}

\section{Case Selection}

In addition to IS (which was the major focus of our previous research), we selected HTS and AAS for analysis herein for three primary reasons. Firstly, accounts either directly associated with them and/or their representatives or accounts supportive of them were some of the most active in our previous analysis. Secondly, similarly to IS, HTS has an international terrorism footprint and may pose a threat to Western publics again in the future; ${ }^{14}$ AAS occupies a more complex position however. At the time the research reported herein was undertaken (i.e. Nov. 2017 to March 2018), Syria, Russia, Iran, Egypt, and the UAE had each designated AAS as a terrorist organization, whilst together, the U.S., Britain, France, and Ukraine blocked a May 2016 Russian proposal to the United Nations to take a similar step. All three groups nonetheless share, to a greater or lesser extent, a commitment to violent jihadi ideology and have witnessed significant crossover of personnel. Third, these three groups have been major players in the Syria conflict. IS was once the largest and most powerful jihadi group in Syria; HTS continues in its role as "the largest non-ISIS extremist group in Syria", 15 and AAS is likely the second largest such group. Once described as "the best-armed and organized militant group in Syria after IS and the Nusra Front",16 in February 2018 AAS amalgamated into the newly established Jabhat Tahrir Suriya (JTS) or Syrian Liberation Front, in which its leaders remain dominant however. ${ }^{17}$ The group nevertheless continues to be referred to as Ahrar al-Sham (AAS) in this article given that was its designation during most of the data collection period. 
Taken together, analysis of IS, HTS, and AAS's online activity supplied us with a detailed snapshot of the Syrian jihadi online ecology in the period November 2017 to March 2018.

\section{Social Media Monitoring Techniques}

The data collection for this project relied upon a combination of direct manual collection and a semi-automated methodology ${ }^{18}$ for identifying pro-jihadi accounts on Twitter; a methodology first deployed in our prior research. ${ }^{19}$ The overall approach was, therefore, a combination of automated and manual, and snowball and purposive sampling methods. Figure 1 illustrates this approach.

\section{Figure 1. Detailed Flow Diagram for Semi-automated Social Media Analysis}

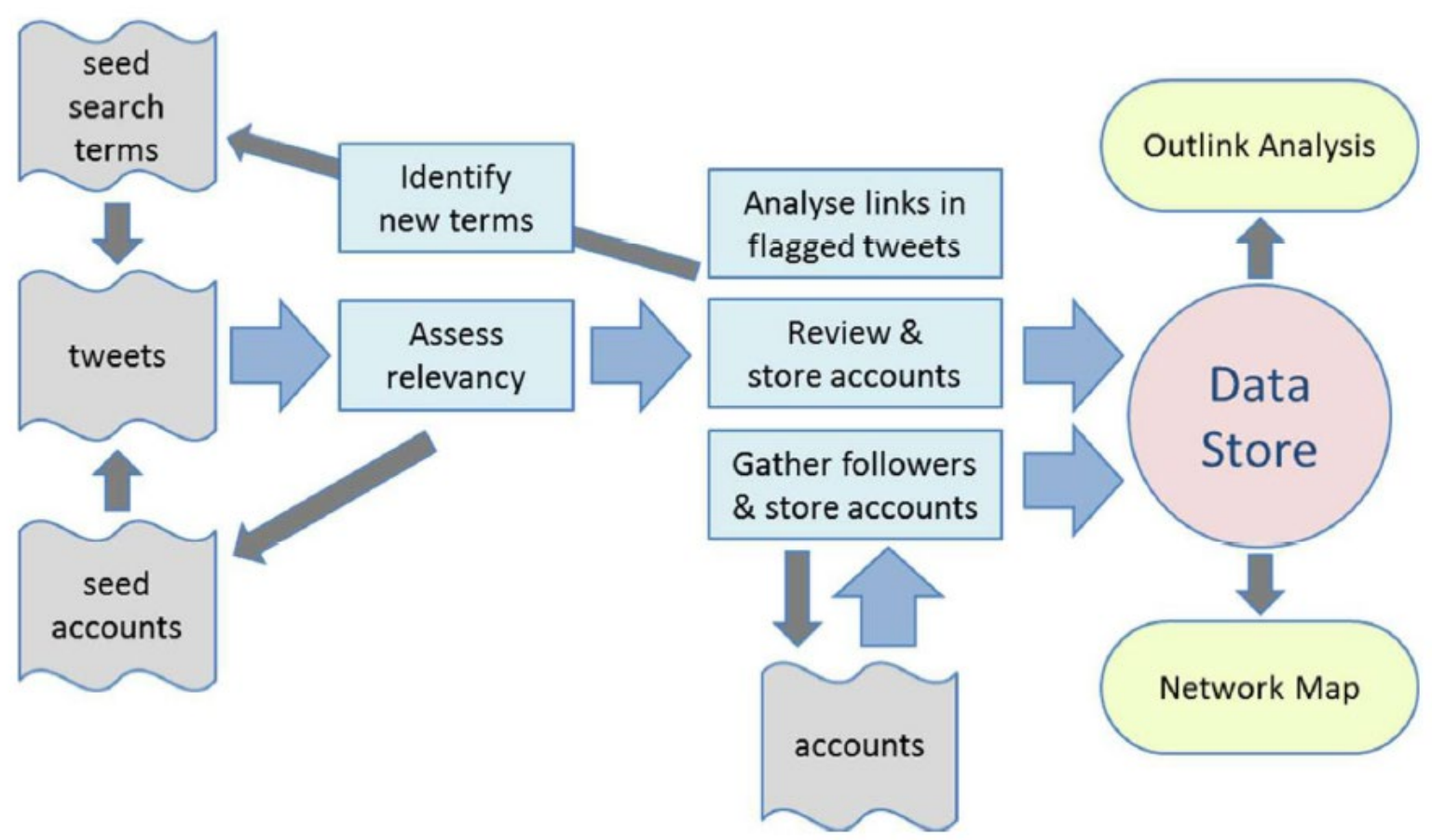

Candidate accounts were identified through finding those accounts that were related to other known accounts of interest ("seed accounts"), or tweets that contained specific terms ("seed search terms"). When a tweet matched these search criteria, further historic tweets were extracted for the candidate account and analyzed to see what proportion were topically relevant, using a machine-learning classifier trained to mimic the classification decisions of a human analyst. Tweets were also assessed for geographic focus, language used, and whether they contained known relevant jihadi terminology and/or iconography and symbols. ${ }^{20}$ This aggregate view of the tweet history of accounts was scored automatically and accounts that exceeded set thresholds were presented to a human analyst for categorization. Using a human analyst for review and categorization ensured that each decision was transparent and understandable, with consistent human level accuracy. ${ }^{21}$ Amongst other things, typical jihadi supporter accounts published tweets, retweeted, and "liked" tweets that supported specific groups' ideology, operations, and leadership; followed a considerable number of other supporters of the same jihadi group and were followed-back by a considerable number of those supporters; and had a profile picture and/or marquee image that supported the group; or some intersection of these considerations. If the analyst confirmed an account was supportive of one of the three jihadi 
groups in our study, any out-links found in the account's tweets were then extracted and analyzed. Information from new confirmed accounts was used by the system in a feedback loop to identify new seed search terms and provide additional seed accounts.

We also reviewed any previously unidentified accounts that were following confirmed jihadi group supporters. ${ }^{22}$ Specifically, we looked for accounts that had embedded themselves within the network by following at least 15 accounts identified as supportive of one of the three jihadi groups we focused upon. ${ }^{23}$ Accounts that fulfilled this criterion were presented to an analyst for manual assessment (semi-automated collection) and then included in the analysis if confirmed as group supporters.

Around $8 \%$ of accounts were highly connected to both HTS and AAS networks making automatic assignment on this basis to just one group uncertain. ${ }^{24}$ However, on examining our manual sample we found that a simple comparison of relative strength of those two relationships (with a suitable threshold) allowed for accurate delineation between HTS and AAS supporter accounts. Overall, using this approach, there was agreement in $90 \%$ of cases between the manual assignment and automatic assignments.

\section{Caveats}

There are a number of caveats attaching to this data collection process:

- Not all the available data was captured. There were various periods of downtime for the semi-automated system throughout the data collection period as the methodology was developed and modified;

- A number of (possibly largely pro-IS) accounts, found through the automated process, were unable to be included due to them being taken down before the system was able to gather a sufficient number of tweets to allow the human analyst to confirm their affiliation;

- A large number of IS accounts (and a small number of HTS and AAS accounts) were first flagged because they had been suspended. They were subsequently manually assessed and confirmed (or otherwise) from an analysis of the content of the accounts' tweets.

\section{Data}

The full and final research dataset comprised 1,236 pro-IS, 1,179 pro-HTS, and 3,782 pro-AAS accounts that were active on Twitter during some or all of the 4-month period between midNovember 2017 and mid-March, 2018 (see Table 1).

Due to the severe disruption of IS by Twitter, the pro-IS dataset contained no official accounts. In fact, official IS accounts were aggressively suspended by Twitter from summer 2014 onward. ${ }^{25}$ The IS dataset was therefore composed largely of "throwaway" accounts. These were specifically created for the purpose of distributing propaganda, not associated with an individual user, generally had no followers, and not intended to be part of an identifiable community, but created only with the expectation that the account would be taken down within a very short period of time (as they mostly were). ${ }^{26}$ 


\section{Table 1. Description of Final Dataset(s)}

\begin{tabular}{|l|r|r|r|r|}
\hline & \multicolumn{1}{|l|}{ IS } & \multicolumn{1}{l|}{ HTS } & \multicolumn{1}{l|}{ AAS } & \multicolumn{1}{l|}{ Total } \\
\hline Number of Accounts & $\mathbf{1 , 2 3 6}$ & $\mathbf{1 , 1 7 9}$ & $\mathbf{3 , 7 8 2}$ & $\mathbf{6 , 1 9 7}$ \\
\hline - of which manually confirmed & 1,236 & 853 & 1,034 & 3,123 \\
\hline - of which Network members & ---- & 326 & 2,748 & 3,074 \\
\hline Method of Collection for Manually-confirmed Accounts \\
\hline - manual collection & 33 & 410 & 295 & 738 \\
\hline - semi-automated collection & 1,203 & 443 & 739 & 2,385 \\
\hline
\end{tabular}

HTS were also circumspect in regards to establishing official accounts or identifying users as official spokespeople or officially associated with the group in some other function. The HTS dataset was, thus, largely composed of "fan" or supporter accounts. The latter type of accounts was defined as supportive of a particular group if their profile picture, marquee image, or bio contained imagery and/or text explicitly associated with that group, and/or they had at least one recent tweet by the user (i.e. not a retweet) that contained images and/or text explicitly supporting the group. Examples included referring to fighters as أسود (i.e. abtaal or heroes) أبطال or آساد (i.e. usood or aasaad, both of which refer to lions), فرسان (i.e. fursan or knights), الاخوة (al ikhwah or "the brothers"). The AAS dataset, on the other hand, contained a mixture of the group's official accounts, accounts of their official representatives, semiofficial accounts, and "fan" or supporter accounts. Included, for example, was the "Official Account of Ahrar Al-Sham Movement" (i.e. @AhrarAl_Sham), which was active at the time of data collection and remained active on 1 June 2019 , some 14 months later, with some $40.2 \mathrm{~K}$ followers, but was later suspended by Twitter. Also included were accounts maintained by AAS's Hasan Soufan (i.e. @hasan0soufan), ${ }^{27}$ then described in his account bio as "Leader of JTS and General Commander of Ahrar Al Sham Islamic Movement", and Omar Khattab (i.e. @omar_khattab4), ${ }^{28}$ described in his bio as "Military Spokesman for Ahrar Al-Sham Movement", but whose account has since been suspended.

Observable for all groups, particularly IS, were users plainly skirting close to, but not contravening Twitter's Terms of Service, in order to avoid account suspension. Advice on how to accomplish this has been provided to IS supporters on other online platforms, including Telegram. ${ }^{29}$ All such implicitly supportive accounts were excluded from our dataset(s).

\section{Differential Disruption}

The findings reported within this section are consistent with observations made in our previous research. ${ }^{30}$ Here it is demonstrated that the disruption to pro-IS accounts on Twitter was sufficiently severe to prevent the formation of a viable community, but that IS activated a large number of "throwaway" accounts on the platform for propaganda distribution purposes, a small proportion of which were not taken down immediately. Observations also suggested that while AAS supporters were subjected to minimal disruption on Twitter, a higher proportion of HTS 
supporters suffered disruption to their activities; however, this interference was not sufficiently grave to prevent the latter forming a viable Twitter community.

Of the 1,236 IS supporter accounts that were observed during the study period of January 2017 to March 2018, under 6\% (69) remained un-suspended at the end of the period-a far higher attrition rate than for the other groups (Table 2). Those that remained online had a median age of 351 days (interquartile range 957 days, or 2 years 7 months), a similar profile to HTS accounts. The research tracked the age at suspension of only 413 out of 1,167 accounts suspended (35\% of the sample) and these accounts had a median age of 18 days (interquartile range 59 days). Unlike the other groups, the vast majority of identified pro-IS accounts were suspended within the time period of the study and results are consistent with the findings in previous research that (i) there is sufficient disruption to ensure a pro-IS community on Twitter is unable to form, but (ii) there continues to be ongoing efforts by IS supporters to distribute propaganda on Twitter using throwaway accounts, met by continuous efforts to disrupt that process. ${ }^{31}$

\begin{tabular}{|l|l|l|l|}
\hline \multicolumn{5}{|c|}{ Table 2. Level of Disruption Per Group } \\
\hline $\begin{array}{l}\text { Percentage of categorised accounts suspended during the study } \\
(\%)\end{array}$ & $7 \%$ & $23 \%$ & $94 \%$ \\
\hline Median age of un-suspended accounts (days) & 752 & 369 & 351 \\
\hline Median age of suspended accounts (days) & 360 & 72 & 18 \\
\hline
\end{tabular}

Disruption of HTS supporters was considerably lower than for IS supporters. Focusing on the subset of accounts that were categorized manually during the study, of the 853 pro-HTS accounts, $77 \%$ remained un-suspended at the end of the period. The median age of these un-suspended accounts was 369 days ( 1 year 0 months), higher than for pro-IS accounts, but significantly lower than for AAS. The interquartile range was likewise smaller at 749 days ( 2 years 1 month). The age of suspension was tracked for most accounts (159/194 - 82\% of sample), outlining a short median lifespan of 72 days (under 3 months) and an interquartile range of 275 days ( 9 months). Most of the suspended HTS accounts tweeted content that violated Twitter's ToS, such as videos/photos containing scenes of violence; tweets explicitly expressing support for HTS and its leadership; and tweets berating other jihadi groups such as AAS and Haraka Nour al-Din alZinki, ${ }^{32}$ amongst others, including issuing threats toward their supporters. Some accounts also appeared to be suspended due to getting into debates with pro-AAS accounts, with some perhaps being reported by their opponents. Overall, HTS supporter accounts survived for a somewhat shorter period than AAS supporters and a higher proportion were shut down within a few months. However, the level of disruption was low enough for HTS supporters to maintain a viable Twitter community.

Of the 1,034 manually identified AAS accounts active during the study time period, 964 (93\%) remained online at the end of the period. The median age of these un-suspended accounts was 752 days ( 2 years 1 month) with an inter-quartile range of 1,053 days ( 2 years 11 months). In total, the research tracked the age on suspension of 58 out of the 70 AAS accounts that were suspended (83\% of the sample) and found a median age of 360 days at the time of their suspension (638 day inter-quartile range). In a similar way to the suspended HTS accounts, most 
of the suspended AAS accounts also tweeted content that violated Twitter's ToS. This included tweeting or retweeting violent content including, for example, images posted by HTS and other jihadi groups showing dead Syrian Arab Army (SAA), Kurdish (YPG), or IS fighters. In addition, a number of pro-AAS accounts were shut down after opponents reported them to Twitter, but with some restored later. It is worth noting here that offensive strategic reporting by groups' supporters of their opponents' accounts is not new nor restricted to Twitter, but observable across a variety of platforms including, for example, Telegram, up to time of writing.

Overall, in the period studied, Twitter's disruption efforts remained heavily tilted toward IS supporters. Of the accounts that were observed being suspended during the study, $81 \%$ of those that we manually categorized were found to be linked to IS. A further $14 \%$ were HTS accounts, and only 5\% AAS accounts. Differential disruption thus continued to be an important feature of the Syrian jihadi Twitter ecosystem.

\section{Wider Syrian Jihadi Online Ecology}

Twitter, due partly to its 280 characters per tweet limit (i.e. micro-blogging function), can serve as a "gateway" platform to other social networking sites and a variety of other online spaces; in effect, in this case, the wider Syrian jihadi online ecology. This section addresses the Twitter outlinking patterns of IS, HTS, and AAS supporters, with a particular focus on the types and purposes of the platforms being out-linked to from each and the implications of this. The analysis in this section relies upon a sub-sample of data from the overall dataset(s), comprising data from the manually inspected accounts associated with IS, HTS, and AAS, that were added either by a human analyst or through the semi-automated process described in the methodology section (see Table 3; see also Table 1).

Table 3. Summary Network Statistics for Automatically Induced Network Communities

\begin{tabular}{|l|l|l|l|l|}
\hline & IS & HTS & AAS & Total \\
\hline No. of Accounts & 1,216 & 764 & 959 & 2,939 \\
\hline No. of Tweets & 49,251 & 157,107 & 180,493 & 386,851 \\
\hline No. of Out-links & 5,371 & 12,469 & 15,811 & 33,651 \\
\hline $\begin{array}{l}\text { \% of Tweets Containing Out- } \\
\text { links* }\end{array}$ & $10.9 \%$ & $7.9 \%$ & $8.8 \%$ & $8.7 \%$ \\
\hline
\end{tabular}

Intra-Twitter Links versus Out-Links

The external (URL) links in a Twitter dataset comprise two types: out-links to other external URLs (web addresses), and intra-Twitter links to a Twitter URL. An intra-Twitter link, which is a direct pointer placed within a tweet to another tweet, is created whenever someone uses the "Quote Tweet" function in their message. The use of the "Quote Tweet" function is now popular across the global Twitter community and is likewise commonly seen in these datasets. Of all the links observed in the dataset, a substantial proportion was intra-Twitter links: 3,646 or $40.4 \%$ of proIS, 8,612 or $40.9 \%$ of pro-HTS, 8,821 or $35.8 \%$ of pro-AAS links. Both out-links and intra-Twitter links operate in a similar fashion: by clicking on the link the user is taken to another location (where they might see new content or in turn be directed to another space). However, the latter do not, in themselves, take users outside the "Twitter universe" - thus, these have been omitted from this analysis of the use of Twitter as a gateway to other platforms. ${ }^{33}$ 


\section{Preferred Other Online Platforms: Overview}

URLs contained in tweets that navigate users away from Twitter are known as out-links. There is a concentration here on the core, or top-level domains, identified in the URLs, so not the content of out-links per se, but instead the platforms out-linked to. This was accomplished by automatically extracting all out-links from the accounts of interest and storing them in the research database. From there, relevant top-level domain information from each out-link was extracted, discarding the individual link information. For example, all links to British Broadcasting Corporation (BBC) content (e.g. http://www.bbc.co.uk/news/world-middle-east41945189) were recorded as "BBC" for out-link analysis purposes. In addition, certain domains were aggregated, where appropriate, into a single category. For example, "www.facebook.com" and "web.facebook.com" were both categorized as "facebook".

The total number of discrete top-level domains identified across the three groups (i.e. IS, HTS, AAS) was over 2,200 . The top out-links from each group was dominated by a relatively small number of platforms, with each then displaying a very long "tail" of social media platforms, websites, and other online spaces that were linked to only once or twice. Table 4 demonstrates the number of out-links for each of the three groups. The table has, however, been organized to represent (a) the Top 30 most out-linked to platforms/sites and (b) the remainder of the outlinks. The latter has been labeled as the "tail" due to the number of times each platform/site is represented dramatically reducing, where, toward the end of the tail, it represents merely one or two "hits". The long tail, thus, has much fewer out-links, as compared to the Top 30, even though they represent a much greater number of platforms/sites. A standard power-law probability distribution was apprehensible here, in other words.

\section{Table 4. Number of Links to Top 30 Out-linked to Platforms Versus Number of Links in} Long Tail of Other Platforms/Sites Out-linked To

\begin{tabular}{|l|l|l|l|l|l|l|}
\hline & \multicolumn{3}{|l|}{ Pro-IS } & \multicolumn{2}{l|}{ Pro-HTS } & \multicolumn{2}{l|}{ Pro-AAS } \\
\hline Out-links & No. & $\%$ & No. & $\%$ & No. & $\%$ \\
\hline Top 30 Out-linked Platforms/Sites & 3,661 & $80.7 \%$ & 9,290 & $84.8 \%$ & 13,522 & $90.6 \%$ \\
\hline Tail & 1,710 & $19.3 \%$ & 3,179 & $15.2 \%$ & 2,289 & $9.4 \%$ \\
\hline TOTAL & $\mathbf{5 , 3 7 1}$ & $\mathbf{1 0 0 \%}$ & $\mathbf{1 2 , 4 6 9}$ & $\mathbf{1 0 0} \%$ & $\mathbf{1 5 , 8 1 1}$ & $\mathbf{1 0 0 \%}$ \\
\hline
\end{tabular}

The remainder of this section focuses on IS, HTS, and AAS's Top 30 most out-linked to platforms/sites (see Table 5), as this covers a minimum of $80 \%$ of all out-links distributed by each group. Each of these Top 30 most out-linked to platforms/sites were manually categorized according to a bespoke coding scheme developed for the project. This scheme focused upon the Type, Purpose, and, if relevant, Sub-type of each online space out-linked to. The five Types of spaces identified were Social Media, Website, Messaging/Telephony, Content Hosting, and Other. ${ }^{34}$ As represented in Table 6, the overall jihadi online ecology was heavily dominated by social media platforms, but with traditional websites playing a not insignificant role. Messaging/Telephony and Content Hosting sites played negligible overall roles. Within the Top 30 listing, Telegram was the only out-linked to space that appeared within the "Messaging/Telephony" "Type". 


\begin{tabular}{|c|c|c|c|c|c|c|}
\hline Rank & Islamic State (IS) & $\begin{array}{l}\text { No. } \\
\text { of } \\
\text { Out- } \\
\text { links }\end{array}$ & $\begin{array}{l}\text { Hay'at Tahrir al- } \\
\text { Sham (HTS) }\end{array}$ & $\begin{array}{l}\text { No. } \\
\text { of } \\
\text { Out- } \\
\text { links }\end{array}$ & $\begin{array}{l}\text { Ahrar al-Sham } \\
\text { (Ahrar) }\end{array}$ & $\begin{array}{l}\text { No. } \\
\text { of } \\
\text { Out- } \\
\text { links }\end{array}$ \\
\hline 1. & $\begin{array}{l}\text { google-drive-photos- } \\
\text { image }\end{array}$ & 587 & youtube & 2230 & youtube & 4,281 \\
\hline 2. & youtube & 454 & du3a.org & 1324 & facebook & 2,679 \\
\hline 3. & archive.org & 250 & telegram & 1249 & telegram & 2,148 \\
\hline 4. & archive_obscure & 243 & facebook & 1166 & du3a.org & 1,744 \\
\hline 5. & justpaste & 217 & eldorar.com & 751 & d3waapp.org & 514 \\
\hline 6. & pc.cd & 215 & wikimapia.org & 383 & justpaste & 306 \\
\hline 7. & du3a.org & 190 & babalhawa.net & 345 & nedaa-sy.com & 169 \\
\hline 8. & reuters & 148 & d3waapp.org & 305 & aldorars.com & 152 \\
\hline 9. & $\begin{array}{l}\text { play-sites-account- } \\
\text { news-google }\end{array}$ & 144 & zad-muslim.com & 203 & ghared.com & 148 \\
\hline 10. & dropbox & 121 & aljazeera & 135 & instagram & 141 \\
\hline 11. & tune.pk & 119 & justpaste & 119 & aljazeera & 109 \\
\hline 12. & ok.ru & 86 & instagram & 116 & eldorar.com & 96 \\
\hline 13. & dailymotion.com & 79 & MedicalAidSyria & 110 & buff.ly & 88 \\
\hline 14. & telegram & 74 & aa.com & 75 & turkpress & 85 \\
\hline 15. & facebook & 73 & mepanews.com & 73 & 7asnat.com & 78 \\
\hline 16. & cloud.mail.ru & 70 & pscp.tv & 72 & $\begin{array}{l}\text { google-drive- } \\
\text { photos-image }\end{array}$ & 72 \\
\hline 17. & twitlonger.com & 62 & alemara1.net & 69 & wikimapia.org & 71 \\
\hline 18. & wikimapia.org & 59 & ghared.com & 59 & pscp.tv & 71 \\
\hline 19. & trackingterrorism.org & 54 & soundcloud.com & 57 & zad-muslim.com & 63 \\
\hline 20. & aljazeera & 49 & guardian & 46 & fllwrs.com & 61 \\
\hline 21. & $\mathrm{rt}$ & 48 & whounfollowedme.org & 46 & aa.com & 58 \\
\hline 22. & streamable.com & 45 & ogn.news & 44 & shaam.org & 57 \\
\hline 23. & vimeo.com & 41 & $\mathrm{rt}$ & 43 & Quran.to & 48 \\
\hline 24. & sendvid.com & 37 & vimeo.com & 42 & syrianoor.net & 46 \\
\hline 25. & $\mathrm{bbc}$ & 36 & sn $4 \mathrm{~h}$ & 40 & yenisafak.com & 42 \\
\hline 26. & amazon.com & 36 & bbc & 39 & sn4h & 41 \\
\hline 27. & soundcloud.com & 33 & orient-news.net & 39 & rfsmediaoffice.com & 41 \\
\hline 28. & my.mail.ru & 32 & $\begin{array}{l}\text { smartnews- } \\
\text { agency.com }\end{array}$ & 39 & orient-news.net & 38 \\
\hline 29. & siteintelgroup & 30 & reuters & 37 & trtarabic.tv & 38 \\
\hline 30. & instagram & 29 & washingtonpost.com & 34 & secure.avaaz.org & \\
\hline
\end{tabular}

\section{Social Media}

Given the dominance of the Social Media and Website Types, which together accounted for over $80 \%$ of all out-links, these were disaggregated further according to their Purpose. For Social Media, these Purposes were Image Sharing, Live Streaming, Microblogging, Social Media Add-on, Social Networking, Sound Sharing, Video Sharing, and Wiki. Table 7 shows that the category Social Media Add-on just edged out Social Networking for the top overall Purpose for Social Media activity. This is a somewhat erroneous finding, which can be explained by a small number of users utilizing, predominantly religious, Social Media Add-on apps such as du3a.org, 3waapp.org, zadmuslim.com that automatically posted to users' Twitter timelines. Such automated posts can account for upward of 24 links per day per user (i.e. one per user per hour) and generally take the form of religious edicts and prayers. Aside from religious commitment, another potential reason for overwhelming Twitter feeds with this type of content could be to try and "hide" extremist content, in order to avoid disruption. 
Table 6. Types of Other Online Spaces Out-linked to By Jihadis From Twitter

\begin{tabular}{|l|l|l|l|l|l|l|l|l|}
\hline & \multicolumn{3}{|l}{ Pro-IS } & \multicolumn{2}{l}{ Pro-HTS } & \multicolumn{2}{l|}{ Pro-AAS } & \multicolumn{2}{l|}{ TOTAL } \\
\hline Type/Out-links & No. & $\%$ & No. & $\%$ & No. & $\%$ & No. & $\%$ \\
\hline Social Media & 1,257 & 34.33 & 6,003 & 64.61 & 9909 & 73.28 & 17,169 & 64.85 \\
\hline Website & 365 & 9.96 & 1919 & 20.65 & 1009 & 7.46 & 3293 & 12.43 \\
\hline $\begin{array}{l}\text { Messaging/ } \\
\text { Telephony }\end{array}$ & 74 & 2.02 & 1249 & 13.44 & 2148 & 15.88 & 3471 & 13.11 \\
\hline Content Hosting & 1,606 & 43.86 & 119 & 1.28 & 378 & 2.79 & 2103 & 7.94 \\
\hline Dead Link & 215 & 5.87 & ----- & ---- & 78 & 0.57 & 293 & 1.10 \\
\hline Other & 144 & 3.93 & ---- & ---- & ----- & ---- & 144 & 0.54 \\
\hline TOTAL & 3,661 & 100 & 9290 & 100 & 13,522 & 100 & 26,473 & 100 \\
\hline
\end{tabular}

Table 7. Purpose of Other Social Media Platforms Out-linked to By Jihadis From Twitter

\begin{tabular}{|l|l|l|l|l|l|l|l|l|}
\hline & \multicolumn{3}{|l}{ Pro-IS } & Pro-HTS & \multicolumn{2}{l|}{ Pro-AAS } & \multicolumn{2}{l|}{ TOTAL } \\
\hline $\begin{array}{l}\text { Purpose/ } \\
\text { Group }\end{array}$ & No. & No. & $\%$ & No. & $\%$ & No. & $\%$ \\
\hline $\begin{array}{l}\text { Social Media } \\
\text { Add-on }\end{array}$ & 252 & 20.04 & 1,937 & 32.26 & 2,666 & 26.90 & 4,855 & 28.27 \\
\hline $\begin{array}{l}\text { Social } \\
\text { Networking }\end{array}$ & 191 & 15.19 & 1,166 & 19.42 & 2,679 & 27.03 & 4,036 & 23.50 \\
\hline Video Sharing & 693 & 55.13 & 2,272 & 37.84 & 4,281 & 43.20 & 7,246 & 42.20 \\
\hline Wiki & 59 & 4.69 & 383 & 6.38 & 71 & 0.71 & 513 & 2.98 \\
\hline Image Sharing & 29 & 2.30 & 116 & 1.93 & 141 & 1.42 & 286 & 1.66 \\
\hline Live Streaming & ----- & ----- & 72 & 1.19 & 71 & 0.71 & 143 & 0.83 \\
\hline Sound Sharing & 33 & 2.62 & 57 & 0.94 & ---- & ---- & 90 & 0.52 \\
\hline TOTAL & 1,257 & $100 \%$ & 6,003 & $100 \%$ & 9,909 & $100 \%$ & 17,169 & $100 \%$ \\
\hline
\end{tabular}

Social Media Add-ons aside, the Social Media category was dominated by just two Purposes, Social Networking and Video Sharing. The Social Networking category included a variety of both high profile and less well known social media platforms, including Facebook, on the one hand, and Russia's Odnoklassniki, on the other. The Video Sharing category presents similar findings, including both large (e.g. YouTube) and a variety of smaller (e.g. Dailymotion, Tune Pakistan) platforms. In both categories, however, it was the large and high-profile platforms that dominated 
with, for example, Facebook and YouTube accounting for $98 \%$ and $96 \%$ of all out-links in their respective categories.

\section{(News) Websites}

For the Website category, the identified Purposes were Activism, Entertainment, Fundraising, News, Other Politics/World Affairs, and Other. In terms of Purpose, News dominated the Website category, accounting for $62.5 \%$ of all entries. The News category was, therefore, further sub-typed into Agency/Wire, Multiple, Online Only, Press, Radio, and Television. This sub-category was dominated by outlets that operate solely online ("Online Only"). These Online Only sites represented 18 of the Top 30 most out-linked to platforms/sites for the three groups combined. This included the overall top-linked to News Website eldorar.com (849 links), which described itself in its Twitter bio-@dorarsite account since suspended-as a "Media project concerned with the Syria - Lebanon - Palestine - Jordan". However, an analysis of the website showed that it to be a pro-Syrian opposition site publishing news from a "rebel perspective", including statements from organizations such as AAS, HTS, Jaysh Al Islam, Nour al-Din al-Zinki, and a number of others. Having said this, a range of more traditional news media outlets were also represented in the Top 30. This included six television stations (including Al-Jazeera (367 links), the BBC (198 links), RT.com (140 links), and CNN (83 links)); four press agencies or news wires (including Reuters (261 links) and Turkey's state-run Andalou Agency (160 links)); and three newspapers (The Guardian (132 links), the pan-Arab daily Al Quds Al Arabi (59 links), and the conservative Turkish daily Yeni S,afak (54 links)). After News, the next most popular Website category, representing $21.4 \%$ of out-links, were dedicated websites maintained by a variety of extremist groups (e.g. Hizb ut-Tahrir, al-Shamiah Front) besides those three focused upon herein.

\section{Messaging/Telephony: Telegram}

Telegram is described on its website as "a messaging app with a focus on security and speed". ${ }^{35}$ In terms of Type therefore, it was included, for analysis purposes, in the Messaging/Telephony category and not, for example, Social Media. ${ }^{36}$ Telegram is worth commenting upon separately here because it is presently the most-preferred online platform of pro-IS users. ${ }^{37}$ This, however, was not evident in the analysis for this piece of research, as out-links to Telegram composed just $1.3 \%$ of all pro-IS accounts' Twitter out-links. ${ }^{38}$ This is in contrast to other parties to the Syria conflict: pro-HTS accounts in our dataset linked to Telegram 1,249 times, representing 10\% of their total out-links, while AAS-related Twitter accounts shared 2,148 links to Telegram, composing almost $13.6 \%$ of their total out-links.

\section{Preferred Other Online Platforms by Group}

\section{Pro-Islamic State Accounts}

There was significant variation in individual users out-linking practices, with some being very heavy out-linkers and others very much intra-Twitter. Pro-IS users displayed a pattern distinct from others, however, relying heavily on out-linking due to the nature of their accounts (i.e. throwaway) and the disruption they faced by Twitter. Overall, pro-IS accounts were far more 
likely to tweet links to content hosting sites, than supporters of HTS or AAS, for example. This amounted to $43.9 \%$ of out-links from pro-IS users to Content Hosting sites, including in top place a variety of Google sites, such as Drive, Photos, etc., and a variety of other similar sites (including justpaste.it, archive.org, and Dropbox, for example). At least one reason for this heavy reliance on hosting sites, in the face of disruption by an increasing array of social media and other platforms, is for these sites to act as back-up "drives" that can be resorted to when content is deleted from higher profile online spaces.

Increased reliance on content hosting sites due to disruption of pro-IS users and content by social media companies is detrimental to IS supporters' public outreach activity. Most content upload sites are not searchable (either by, for instance, Google or internally), for example, and their content can therefore only be accessed by possession of dedicated URLs, which limits its wider availability. Many content upload sites also have no or only very rudimentary recommendation capabilities, ${ }^{39}$ in contrast to their social media counterparts. These are drawbacks from the perspective of engaging in wide online public outreach.

Having said this, in addition to Content Hosting sites, Video Sharing platforms also featured prominently, with YouTube ranking second for overall out-links from pro-IS Twitter accounts, despite being under considerable pressure from policymakers to stepup the disruption of ISrelated activity on their platform. In fourteenth place, accounting for 119 out-links from pro-IS accounts, was the video sharing platform tune.pk, which is similar in nature to YouTube, but hosted in Pakistan. This platform was linked-to by an array of accounts, but most of which had a common characteristic, screen names and @handles constructed of random letters and numbers, indicating that they were set-up specifically to avoid disruption and potentially as "throwaway accounts". Tune.pk provides an alternative to YouTube, with a simple search on the platform returning multiple pro-IS videos, some of which were extremely violent in nature.

\section{Pro-Hayat Tahrir Al Sham (HTS) Accounts}

Pro-HTS supporters out-links amounted to 12,469 , representing $24.9 \%$ of all out-links in the overall dataset. The Top 30 out-linked-to sites for HTS were dominated by Websites (16/30) and Social Media platforms (12/30). When considering the numbers of out-links to these two different types of online spaces, however, the total number of Websites $(1,885)$ was less than a third of those to Social Media platforms $(6,003)$. The Video Sharing platform YouTube appeared in top position for pro-HTS users' out-links, with some 2,230 hits. A substantial portion (35.1\%) of other out-links in the Social Media category was accounted for by Social Media Add-ons, whereby users allowed applications to post religious messages, in the form of tweets, automatically to their timelines. The Website category, on the other hand, was dominated by News sites. Although major global news corporations, including the BBC and Reuters appeared, they did so lower down in Table 5 (i.e. at no. 27 and no. 30 respectively). The preferred news website for pro-HTS accounts was eldorar.com (described earlier) (751), which, despite their relatively low overall level of out-linking, caused it to be the most outlinked-to site overall in the category Website/News. 


\section{Pro-Ahrar Al Sham (AAS) Accounts}

Pro-AAS accounts had the highest rate of out-links, with 15,811, which accounted for $31.5 \%$ of the entire out-link sample across all three groups. Social Media dominated the pro-AAS out-links, with YouTube and Facebook the first and second most out-linked to platforms, respectively. Combined, these two accounted for $51.5 \%$ of the total outlinks for the Top 30 most out-linked to online spaces by pro-AAS Twitter accounts (Table 5). When broken down, YouTube was outlinked to 4,281 and Facebook 2,679 times. The Messaging/Telephony application, Telegram came in at number three in the pro-AAS Top 30 most linked-to platforms, with a total of 2,148 out-links, representing $15.9 \%$ of the Top 30 sample. As with HTS, Social Media Add-ons of a religious nature, operating on the Twitter platform, also featured amongst pro-AAS users, but not as prominently. From fourth position onward the numbers of out-links drop precipitously, from 1,744 in fourth, to 514 in fifth, and to under 100 from 13th position onwards (Table 5). This indicates that while News websites featured strongly in the table-with AAS and supporters relying on news from both media corporations like Orient News and al-Jazeera, and from small-to-medium internet and media companies, including Turkpress and Syrian Noor-these did not account for very large numbers of out-links overall, especially as compared to Social Media platforms.

\section{Conclusion}

There has been a tendency with regard to the Syria conflict for academic and other researchers, along with media, policymakers, and social media companies, to focus predominantly upon IS's online activity to the exclusion of the online activity of other parties to the conflict. In this article, we focused on not just IS, but a number of other Syria-based purveyors of violent jihadi ideology, namely HTS and AAS, and their online supporters.

Considerable variation-what we term "differential disruption"-was observed as regards Twitter's disruption of the three groups studied in 2017 and 2018. Unsurprisingly, pro-IS accounts were found to be the most highly pressured, with a disruption rate upwards of $94 \%$. Pro-HTS accounts, even though they were the second most disrupted group, only had a disruption rate of some $23 \%$, which gave them considerable ongoing traction on the Twitter platform. ProAhrar accounts were found to be even freer in their activity subject to levels of disruption of just $7 \%$. It appears that, in effect, Twitter's disruption activity correlated with the perceived level of "real world" terrorism threat posed to the West by particular groups and their supporters.

In terms of the wider Syrian jihadi online ecology, there was a focus upon the variety of platforms out-linked to from Twitter by pro-IS, pro-HTS, and pro-AAS accounts. Despite the overall number of discrete platforms and sites out-linked to being well over 2,000, this was heavily dominated by links to social media platforms, particularly major social media sites, including Facebook and YouTube. ${ }^{40}$ In addition, websites, particularly News websites, were also shown to be important nodes in the jihadi online ecology. These included not just local and regional outlets, whether professional or engaged in so-called "citizen journalism" activity, but also major global media corporations, such as al-Jazeera, the BBC, CNN, and RT. The role of news media in contemporary extremist and terrorist online ecologies has been largely overlooked to-date and, in fact, is probably under-estimated here given that a proportion of the content being circulated on the social media platforms identified (e.g. Facebook, YouTube) was also likely drawn from news media sources. 
The most salient difference between the groups was pro-IS users' outsized reliance on content hosting sites. This reflects the fact that, of the three groups studied, IS were and are presently under the most pressure, both in the "real world" and online. Pro-IS accounts are being significantly disrupted on major social media and other prominent online platforms and, outside of Telegram, they must rely on a variety of other, often quite obscure, platforms to diversify their online presence. HTS and AAS, on the other hand, have a relatively uninterrupted presence on a diversity of platforms, including major social media sites.

\section{Future Research}

We suggest that there are at least two major avenues of future research arising from this work. The first relates to out-link analysis and has at least two parts. Initially, a more granular categorization of the Top 30 most out-linked to platforms by each group from Twitter should be undertaken. This could include, but need not be limited to, addition of a Language category. Anecdotally, for example, in this analysis we encountered sites and/or content in Arabic, Bahasa/Indonesian, Bengali, English, Farsi, French, German, Pashto, Russian, Spanish, Turkish, and Urdu. An analysis of which groups were linking to content in what languages would provide useful additional insights about groups' network members and target audience(s). The second issue arising from this research to pursue further is the long tail of platforms and sites out-linked to by the groups studied, but falling outside of the Top 30 lists focused upon here. The UN Counter-terrorism Directorate (UNCTD)-sponsored Tech Against Terrorism project is tasked with, amongst other things, supporting small and medium Internet companies in responding to the risks associated with hosting terrorism content on their platforms. ${ }^{41}$ One of the things that analysis of this sort does is draw attention to the rather large number of these that are currently hosting-admittedly small amounts on the basis of out-link counts-such content and what functionalities of these platforms are particularly salient to extremists and terrorists and their supporters at any given time.

Second, the authors have consistently maintained that a narrow focus on IS and its supporters' online activity is too reductionist. This is at least one of the reasons for the focus in this article on IS activity as a component of a wider Syrian jihadi online ecology, including-but certainly not limited to-HTS and AAS. There is no reason why such analyses should be restricted to violent jihadi online activity; this analysis could be usefully extended in various directions. The approach described herein could be used to more thoroughly analyze online activity in the Syria conflict more broadly by integrating data on other major parties to the conflict such as, for example, the online activity of non-jihadi opposition groups, the Assad government, and Shi'a militias. If a focus on militants and terrorists were to be maintained, a comparison of our findings with the online activity of other similar entities in the region (e.g. Hamas, Hizbollah, Iraq's Popular Mobilization Units, Yemen's Houthis) would be appropriate.

Furthermore, a 2016 analysis of extreme right Twitter out-linking practices had similar findings to those contained in this article:

YouTube was the top linked-to platform from Twitter in our exploratory analysis of all out-links from a sample of 175 European extreme right Twitter accounts. The next most prevalent links were to a selection of ideologically consistent news websites, including express.co.uk, dimissionietuttiacasa.com, breitbart.com, dailymail.co.uk, and rt.com. Similar to the pro-IS outlinks, traditional mass media outlets, particularly newspapers, were identified as prominent nodes 
in the European extreme right online scene; blogs also remain conspicuous components of the same scene. ${ }^{42}$

Similar results were reported by J.M. Berger in his Alt-Right Twitter census. ${ }^{43}$ A larger scale and more up-to-date analysis of the wider extreme right online ecology, not just in the U.S., but covering the U.K., and Western Europe more widely, could lead to useful insights as regards the similarities and differences between this and the jihadi online ecology, some of which are already apparent in the above quote. Nor is Twitter required to be the "gateway platform" for such research. Telegram would, for example, be an appropriate starting point for out-link analyses of either or both of contemporary jihadi and extreme right online ecologies. A project employing multiple platforms as "gateways", would supply an even more detailed snapshot of the chosen online ecology/ecologies.

\section{Endnotes}

${ }^{1}$ Maura Conway, Moign Khawaja, Suraj Lakhani, Jeremy Reffin, Andrew Robertson, and David Weir, "Disrupting Daesh: Measuring Takedown of Online Terrorist Material and Its Impacts," Studies in Conflict \& Terrorism 42, no. 1-2 (2018): 141-160.

${ }^{2}$ Ibid., $146-148$ and $150-152$.

${ }^{3}$ Ibid., 152-153.

${ }^{4}$ Ibid., 152 and 157; see also Maura Conway, "Determining the Role of the Internet in Violent Extremism and Terrorism: Six Suggestions for Progressing Research," Studies in Conflict \& Terrorism 40, no. 1 (2017): 85 and 88.

5 Ken Wolf, "An Analysis of Islamic State Propaganda Distribution," Flashpoint, 2018, 8, accessed May 18, 2020, https://go.flashpoint-intel.com/docs/an-analysis-of-islamic-statepropaganda-distribution.

${ }^{6}$ Bennett Clifford, "'Trucks, Knives, Bombs, Whatever': Exploring Pro-Islamic State Instructional Material on Telegram," CTC Sentinel 11, no. 5 (2018): 23-29.

${ }^{7}$ Facebook, "What Types of Organizations Aren't Allowed on Facebook?", Facebook Help, n.d., accessed May 18, 2020, https://www.facebook.com/help/1738430046395200?helpref=related.

8 Maura Conway, "Routing the Extreme Right: Challenges for Social Media Platforms," RUSI Journal 165, no. 1 (2020): 3.

9 Casey Man Kong Lum, "Introduction: The Intellectual Roots of Media Ecology," New Jersey Journal of Communication 8, no. 1 (2000): 1-7.

10 Akil Awan, Andrew Hoskins, and Ben O'Loughlin, Radicalisation and the Media: Connectivity and Terrorism in the New Media Ecology (London and New York: Routledge, 2011).

${ }_{11}$ Geoffrey C. Bowker and Susan Leigh Star, Sorting Things Out: Classification and its Consequences (Cambridge, MA: MIT Press, 1999), 47.

12 Bennett Clifford and Helen Powell, "Encrypted Extremism: Inside the English-Speaking Islamic State Ecosystem on Telegram" (Washington, DC: GWU Program on Extremism, 2019), accessed May 18, 2020, https://extremism.gwu.edu/sites/g/files/zaxdzs2191/f/EncryptedExtremism.pdf; Stuart Macdonald, Daniel Grinnell, Anina Kinzel, and Nuria Lorenzo-Dus, "Daesh, Twitter and the Social Media Ecosystem: A Study of Outlinks Contained in Tweets Mentioning Rumiyah," RUSI Journal 164, no. 4 (2019): 60-72. See also Ali Fisher, Nico Prucha, and Emily Winterbotham, "Mapping the Jihadist Information Ecosystem: Towards the Next Generation of Disruption Capability" (RUSI, London: GNET, 2019), accessed May 18, 2020, https://rusi.org/sites/default/files/20190716_grntt_paper_06.pdf; Niall F. Johnson, Minzhang Zheng, Yulia Vorobyeva, Andrew Gabriel, Hong Qi, Nicolás Velásquez, Pedro Manrique, Douglas Johnson, Elvira María Restrepo, and Chaoming Song. "New Online Ecology of Adversarial Aggregates: ISIS and Beyond," Nature 352, no. 6292 (2016): 1459-63.

${ }^{13}$ Conway et al. "Disrupting Daesh: Measuring Takedown of Online Terrorist Material and Its Impacts". 
${ }^{14}$ HTS has often been referred to as al-Qaeda's Syria affiliate, but this is challenged by some analysts, who also view it as much more Syria- than global-focused; see, for example, Tore Refslund Hamming and Pieter Van Ostaeyen, "The True Story of al-Qaeda's Demise and Resurgence in Syria," Lawfare, April 8, 2018, accessed May 18, 2020, https://www.lawfareblog.com/true-story-al-qaedas-demise-and-resurgencesyria; and Charles Lister, "US Officials Just Mislabeled a Syrian Terror Group as al Qaeda. Worse, They're Missing a Far Bigger Threat," Defense One, June 1, 2018, accessed May 18, 2020, https://www.defenseone. com/ideas/2018/06/us-officials-just-mislabeled-syrian-group-al-qaeda-worse-theyre-missing-farbigger-threat/148656/. It is worth noting here too that a new group composing al-Qaeda loyalists and known as Tandhim Hurras al-Deen - the "far bigger threat" referred to by Lister-was established at the end of February 2018 and it is this group that is now viewed by many as al-Qaeda's de facto Syria branch. ${ }^{15}$ Syria Study Group, "Final Report and Recommendations" (Washington DC: USIP, 2019), 22, accessed May 18, 2020, https://www.usip.org/sites/default/files/Syria\%20Study\%20Group\%20Final\%20Report.pdf.

${ }^{16}$ Nusra Front is one of the former designations of HTS. Bassem Mroue, "One of Syria's Most Powerful Rebel Groups is Rebranding itself with Turkey's Backing," Business Insider, October 8, 2015, accessed May 18, 2020, https://www.businessinsider.com/ahrar-al-sham-insyria-and-turkey-2015-10?r=US\&IR=T; see also CISAC, "Ahrar al-Sham," (Mapping Militant Organisations: Stanford University, 2017), accessed May 18, 2020, https://web.stanford.edu/group/mappingmilitants/cgi-bin/groups/view/523.

${ }^{17}$ Hamming and Van Ostaeyen, "The True Story of al-Qaeda's Demise and Resurgence in Syria."

${ }^{18}$ Implemented using the Method52 social media analysis platform; for more information on this, see www.taglaboratory.org.

${ }^{19}$ Conway et al. "Disrupting Daesh: Measuring Takedown of Online Terrorist Material and Its Impacts."

20 Our approach was very similar to that detailed in Valentine Crosset, Samuel Tanner, and Aurélie Campana, "Researching Far Right Groups on Twitter: Methodological Challenges 2.0," New Media \& Society 21, no. 4 (2019): 939-61.

${ }^{21}$ For more, see Deven Parekh, Amarnath Amarasingam, Lorne Dawson and Derek Ruths, "Studying Jihadists on Social Media: A Critique of Data Collection Methodologies," Perspectives on Terrorism 12, no. 3 (2018): 3-21, in which our methodology is discussed and compared with others. See also Margeret Hall, Michael Logan, Gina S. Ligon, and Douglas C. Derrick, "Do Machines Replicate Humans? Toward a Unified Understanding of Radicalizing Content on the Open Social Web," Policy \& Internet 12, no. 1 (2020): 109138.

${ }^{22}$ Any Twitter account can choose to follow another account.

${ }^{23}$ Accounts that had more than 5,000 followers were also excluded in order to focus the analysis on 'local' inter-personal relations rather than on 'celebrities' or other types of high-profile accounts, which were followed by a wide range of interested parties (e.g. other parties to the conflict, journalists, researchers, etc.).

${ }^{24}$ These included accounts that regretted or condemned the infighting between HTS and Ahrar and urged unity in the fight against their common enemy (i.e. the Syrian regime); accounts that praised influential Islamic scholars (e.g. Saudi cleric Sheikh Abdullah Al Moheisany) who were trying to mediate between HTS and Ahrar; and accounts that were supportive of groups such as Jaish al-Izzah who refused to take sides and focused on attacking the regime.

${ }^{25}$ J. M. Berger and Jonathon Morgan, "The ISIS Twitter Census: Defining and Describing the Population of ISIS Supporters on Twitter" (Washington DC: Brookings, 2015), 23, accessed May 18, 2020, https://www.brookings.edu/wp-content/uploads/2016/06/is,is_twitter_census_berger_morgan.pdf.

${ }^{26}$ Conway et al., "Disrupting Daesh: Measuring Takedown of Online Terrorist Material and Its Impacts," 89 and 16.

${ }^{27}$ This account was active at the time of data collection and remained active on 1 April 2020, showing $26.6 \mathrm{~K}$ followers, but with no bio any longer appearing. Worth noting here too is that Jaber Ali Basha took over leadership of JTS from Soufan in August 2018. Basha's official Twitter account, @JaberAliBasha, had 8,998 
followers on 1 April 2020 and an Arabic language bio reading "General Commander of the Islamic Movement of Ahrar al-Sham."

${ }^{28}$ Khattab's account remained available on 1 June 2019, but with the most recent tweet from 4 February 2018 , and just 1,833 followers.

${ }^{29}$ Clifford, "'Trucks, Knives, Bombs, Whatever': Exploring Pro-Islamic State Instructional Material on Telegram."

${ }^{30}$ Conway et al., "Disrupting Daesh: Measuring Takedown of Online Terrorist Material and Its Impacts," 67 and 12.

${ }^{31}$ Conway et al., "Disrupting Daesh: Measuring Takedown of Online Terrorist Material and Its Impacts."

32 The Nour al-Din al-Zinki Movement was a Syrian Islamist group with previously close ties to, amongst others, HTS, which together with AAS coalesced into JTS in February 2018.

${ }^{33}$ It is worth noting that linking is not the only way in which tweet content can be augmented. Tweets can contain embedded images and videos ("mediaURLs") which can be viewed directly within the tweet without the need to be directed to some other site or platform via a link. The use of embedded photos and (more rarely) videos is common practice. As with Twitter in-linking, embedding content does not take users outside Twitter and is therefore not considered further here.

${ }^{34}$ Worth acknowledging here is the difficulty of classifying some platforms that overlap our categories. For example, we classified YouTube as a Social Media platform with the purpose of Video Sharing rather than a Content Hosting site; conversely Samantha Weirman and Audrey Alexander in their "Research Note: Hyperlinked Sympathizers-URLs and the Islamic State" (Studies in Conflict and Terrorism 43, no. 3 (2020): 239-57) categorise YouTube-along with justpaste.it, archive.org, vid.me, and soundcloud.com - as a filesharing "base domain" (ibid: 247). We based our classification decisions on a combination of the platforms' selfdescriptions and the company descriptors supplied by Google Finance. Prominent on YouTube's About page is its self-description as a place to "listen, share and build community;" Google Finance categorises YouTube as a "video sharing company."

${ }^{35}$ See https://telegram.org/.

36 Google Finance classifies Telegram as simply "software."

${ }^{37}$ Mia Bloom, Hicham Tiflati, and John Horgan "Navigating ISIS's Preferred Platform: Telegram," Terrorism and Political Violence 31, no. 6 (2019): 1242-1254. See also Nick Robins-Early, "How Telegram Became the App of Choice For ISIS," HuffPost, May 24, 2017, accessed May 19, 2020, https://www.huffingtonpost.co.uk/entry/isis-telegram-

app_n_59259254e4b0ec129d3136d5?ri18n=true; Laura Smith, "Messaging App Telegram Centrepiece of IS Social Media Strategy," BBC News, June 5, 2017, accessed May 18, 2020, https://www.bbc.co.uk/news/technology-39743252.

38 This matches previous findings; see Conway et al. "Disrupting Daesh: Measuring Takedown of Online Terrorist Material and Its Impacts," 13.

39 Online recommender systems present content to users of specific platforms that they might not otherwise locate based on, for example, prior search or viewing history on that platform. See Derek O'Callaghan, Derek Greene, Maura Conway, Joe Carthy, and Pádraig Cunningham, "Down the (White) Rabbit Hole: The Extreme Right and Online Recommender Systems," Social Science Computer Review 33, no. 4 (2015): 559-78.

${ }^{40}$ Similar findings have been demonstrated in related research; see, for example, Weirman and Alexander "Research Note: Hyperlinked Sympathizers-URLs and the Islamic State"; Wolf, "An Analysis of Islamic State Propaganda Distribution".

${ }^{41}$ For more, see https://www.techagainstterrorism.org.

${ }^{42}$ Maura Conway, "Violent Extremism and Terrorism Online In 2016: The Year in Review" (Dublin: VoXPol, 2016), 11-12, accessed May 18, 2020, https://www.voxpol.eu/download/vox-pol_publication/YearIn-Review-WEB.pdf.

${ }^{43}$ J. M. Berger, "The Alt-Right Twitter Census Defining and Describing the Audience for Alt Right Content on Twitter" (Dublin: VOX-Pol, 2018), accessed May 18, 2020, https://www.voxpol.eu/download/voxpol_publication/AltRightTwitterCensus.pdf. 